\title{
Interferon discovery and ferret flu
}

Fifty years ago virologists were struggling to understand why an inactivated virus reduced the ability of a normal virus to infect cells - a process called interference. Jean Lindenmann and Alick Isaacs at the National Institute for Medical Research (NIMR) at Mill Hill, London, found the answer in less than a year of intensive and inspired research ${ }^{1,2}$. The inactivated virus triggered the infected cells to produce a protein that suppressed replication of the live virus. The protein, called interferon, turned out to be a useful therapy for hepatitis $C$ and many cancers. Jean Lindenmann, now 83, talks to Nature.

\section{How did you come up with the name interferon?}

I started out studying physics at the University of Zurich, but 18 months into my course the atom bomb was dropped on Hiroshima. This so disenchanted me that I switched to medicine. I guess I was still jealous of all those elementary particles the physicists had to play with - baryons, neutrons and so on - so I created an '-on' suffix for the viral 'interfering' substance we were looking for, and made interferon. At first it was a bit of a joke name, a sort of slang in the lab, but then it stuck.

\section{How was working at the NIMR in 1956?}

It was informal and very intellectual. Isaacs would whistle arias and we'd all have to guess from which opera they came. There was lots of political discussion. It was the time of the Hungarian uprising and the Suez crisis. A petition was circulated to protest the British invasion of Egypt that had nationalized the Suez Canal. But I felt that I shouldn't sign it because Switzerland was a neutral country.

\section{How did you and Isaacs develop your key experiments? \\ We adapted a standard}

experimental model for infection studies that uses the chorioallantoic membrane - the membrane surrounding the growing embryo — in fertilized chicken eggs. The amount of virus generated by infected membranes after each experiment was measured by a bioassay based on the ability of viruses to cause clumping of red blood cells. We used the influenza A virus. Instead of infecting the membrane by injecting the virus into the cavity between the membrane that lines the shell and the embryo - as others did - we peeled the membrane away and cut it into six or eight pieces. We placed each piece in a test tube with nutrient medium. This gave us more experimental values per egg and more experimental flexibility. For instance, we could wash the fragments after each exposure and re-expose

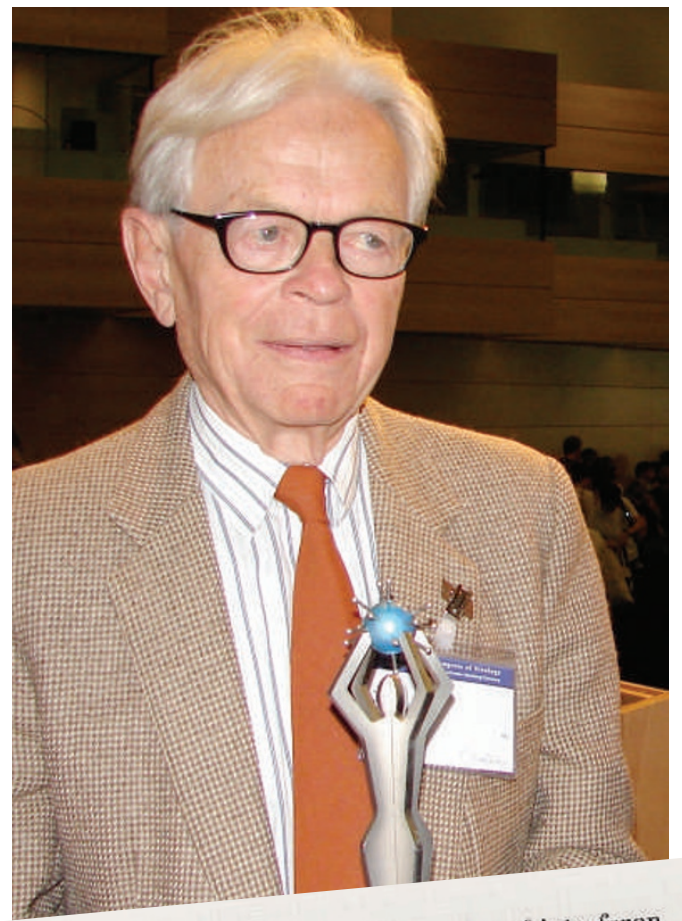

Virus interference. II. Some properties of inter BY A. Isace, J, Lindermank* asd R. C. VAaen National Institule for Medical keseanes

(Communicated by C. H. Ardrewes, P.R.S,-Received 7 Alaren igs7)

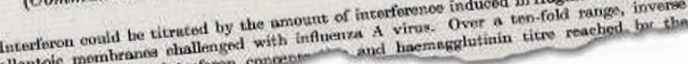
allantole mombianes interforin concen proportion betwe por is challenge vinies

Jean Lindenmann collects the European Virology award on 2 September in Nuremberg, Germany.

them to inactivated or live virus at different times, in different conditions.

\section{Is that why you succeeded where others failed?}

The director of NIMR at the time, Christopher H. Andrewes, had considered the possibility that interference worked by inducing infected cells to produce an antiviral molecule back in 1942, but he was unable to see it in his tissue-culture experiments. Back then, tissue culture was tricky - after two or three days everything would be contaminated with bacteria. It was easier for us to see the phenomenon in tissue culture in the 1950s because we had access to antibiotics such as penicillin and streptomycin. I often reflect that if the Asian flu pandemic had happened in 1956 instead of 1957, we would not have been able to do this work. NIMR virologists would have been completely occupied with public-health-related work.

\section{Was biosecurity strict in the NIMR then?}

Even with freshly isolated strains we took only the ordinary precautions. The first isolation of an influenza virus by Andrewes and Wilson Smith, done by infecting ferrets intranasally, resulted in a lab infection: Andrewes had fallen ill with naturally acquired influenza. Using his nasal washings, they inoculated ferrets. The fever that the animals developed could be passed on to other ferrets. In the course of such a passage, a ferret sneezed into the face of Smith, who fell ill with influenza; from this lab infection the virus strain now known as WS was established. Andrewes jokingly mentioned that actually this strain ought to be called CHA.

\section{Are you disappointed that interferon never became the panacea it was tipped to be?}

Interferon was hyped shamelessly at some phases of scientific research. Of course it never became a miracle cure for cancer and viral infections. Scientists were not innocent in this hyping - it was a way of getting research money. Back in 1957 we were, of course, already thinking about applications, and we patented it. Isaacs enrolled a biochemist to purify and chemically characterize our interferon, expecting it to take six months. In the event it took more than 20 years.

Interview by Alison Abbott.

1. Isaacs, A. \& Lindenmann, J. Proc. R. Soc. Lond. B 147, 258 267 (1957).

2. Isaacs, A., Lindenmann, J. \& Valentine, R. C. Proc. R. Soc Lond. B 147, 268-273 (1957) 